\title{
A crise hídrica no Vale do Sambito: uma perspectiva de desenvolvimento socioambiental
}

\author{
A water crisis in Sambito Valley: a perspective of social and environmental \\ development
}

\author{
Marcos Vinícius Machado de Araújo ', Antônio Felipe da Silva Souza ", Adonys Roney \\ Muniz da Silva III
}

\section{RESUMO}

A crise hídrica no Piauí é um dos fatores que mais castigam a região, repercutindo em várias esferas, como a social e econômica. Os reservatórios estaduais, em grande maioria, são superficiais e em épocas de verão entram em criticidade hídrica, expondo os habitantes a situações críticas de subsistência. Estudos hidrogeológicos, porém, revelam que o Piauí situa-se sobre a bacia de maior potência hídrica subterrânea do nordeste. O presente trabalho objetiva analisar as relações que se estabelecem na sociedade acerca das questões de propriedades ambientais referentes aos recursos hídricos e a sua preservação para compreender o fenômeno de crise hídrica regional. $O$ estudo revelou que os fatores climáticos exercem menor influência que os políticos e socioambientais, a população encontra-se carente de informação independentemente do seu status social e acesso à educação, enquanto o governo em suas diversas esferas encontra-se pouco ou nada mobilizado, desta forma, espera-se que com o presente trabalho tanto a comunidade científica quanto a social e política despertem para se articularem e introduzirem novos hábitos e práticas de consumo do recurso e a sua preservação disponibilizando acesso ao básico de uma vida digna.

Palavras-chave: Crise hídrica; Desenvolvimento socioeconômico; Socioambiental.

\section{ABSTRACT}

The water crisis in Piaui is one of the factors that most punish the region, affecting several spheres, such as social and economic. Most of the state reservoirs are shallow and in summer times they become water critical, exposing the inhabitants to critical subsistence situations. Hydrogeological studies, however, reveal that Piauí is located on the basin of the largest underground water power in the northeast. This paper aims to analyze the relations that are established in society about the issues of environmental properties related to water resources and their preservation to understand the phenomenon of regional water crisis, for such. The study revealed that climate factors have less influence than political and socio-environmental factors, the population is in need of information regardless of their social status and access to education, while the government in its various spheres is little or not mobilized. Thus, it is expected that with the present work, the scientific, social and political

I Mestrando em Meio Ambiente e Desenvolvimento, Departamento de Ciências Ambientais, UFPI. E-mail:
marcos.araujo111@enova.educacao.ba.gov.br. ORCID: https://orcid.org/0000-0003-1854-9651.
"Mestrando em Meio Ambiente e Desenvolvimento, Departamento de Ciências Ambientais, UFPI. E-mail:
felipe.piripiri@hotmail.com. ORCID: https://orcid.org/0000-0003-2329-4104.
III Mestrando em Meio Ambiente e Desenvolvimento, Departamento de Ciências Ambientais, UFPI. E-mail: adonysroney@hotmail.com. ORCID: https://orcid.org/0000-0002-0159-1135. 
community will awaken to articulate and introduce new habits and practices of resource consumption and their preservation, providing access to the basics of a decent life.

Keywords: Water crisis; Socioeconomic development; Socioenvironmental.

\section{INTRODUÇÃO}

Dentre todos os Estados da região nordeste do Brasil e que compõem o Polígono das Secas (Lei 63.778/68), o Piauí caracteriza-se como a região mais rica em recursos hídricos subterrâneos. A bacia do Parnaíba, uma das 26 bacias sedimentares da região, é também uma das maiores em reservas hídricas subterrâneas do Brasil percorrendo toda a extensão territorial do Estado (FEITOSA; VIDAL, 2004). Sendo que, um piauiense possui a sua disposição $\left(9.608 \mathrm{~m}^{3} / \mathrm{hab} / \mathrm{ano}\right)$ relativamente à mesma quantidade de água que um americano $\left(9.940 \mathrm{~m}^{3} / \mathrm{hab} / \mathrm{ano}\right)$, (REBOUÇAS, 1997).

A Secretaria de Meio Ambiente e Recursos Hídricos do Estado (SEMAR) anualmente informa sobre os municípios que estão em estado de alerta ou em emergência (DOE, 2017), trazendo à tona a luz da reflexão o embate entre o potencial hídrico subterrâneo e a constante seca que acomete a região. Não só pelos períodos de estiagem, mas por prejudicar o desenvolvimento socioeconômico da região. Segundo Rebouças (1997):

“O que de fato falta no semiárido não é água, mas determinado padrão cultural que agregue confiança e melhore a eficiência das organizações públicas e privadas envolvidas no negócio da água".

De acordo com o Sistema de Informações de Águas Subterrâneas (SIAGAS), mantido pelo CPRM-Serviço Geológico do Brasil, até 2011 foram registrados 25.345 poços tubulares na região do território piauiense, possuindo assim 123 hab/poço ou 1 poço a cada $10 \mathrm{~km}^{2}$ de forma a ter a maior quantidade de poços cadastrados no Brasil, e, apesar desta quantidade, apresenta problemas de deficiência hídrica, possivelmente por que suas perfurações não sejam planejadas e baseadas em técnicas científicasgeológicas ou por densidade (VASCONCELOS et al., 2014). As técnicas agrícolas utilizadas apresentam-se ainda como uma alternativa ultrapassada, já que muitos 
agricultores lançam mão da irrigação de superfície (FAO, 1988), equipamentos e caracterização de ambientes equivocados, resultando em problemas de infraestrutura. Deste modo, fazem-se necessárias técnicas voltadas para agropecuária, saneamento básico adequado, proteção dos mananciais e uma gestão adequada do crescimento para atender as demandas.

O presente artigo divide-se em quatro capítulos: 1 - Contextualização do Tema: que apresenta as principais características hídricas relevantes do Estado e a contribuição do estudo para a comunidade científica; 2- Delimitação do Espectro de Pesquisa e Material e Métodos: contendo os territórios e suas áreas de estudo e o tipo de pesquisa desenvolvida: qualitativa e quantitativa, através da percepção ambiental da população e uso de software ANOVA para dados estatísticos; 3- Análise de Dados Coletados: com as respectivas informações cedidas pela população dos municípios de Inhuma e Valença do Piauí; 4- Interpretação e Considerações acerca da Análise de Dados: reflexões sobre as questões culturais, sociais, políticas e econômicas.

No presente trabalho objetiva-se analisar as relações que se estabelecem na sociedade acerca das questões de propriedades ambientais referentes aos recursos hídricos e a sua preservação para compreender o fenômeno de crise hídrica regional. Deste modo, procura-se estabelecer a ordem e a gênese da sua escassez na região do semiárido piauiense que, apesar dos períodos secos e chuvosos acentuados, possui água suficiente para a sua população seja nos períodos de precipitações pluviométricas ou em suas bacias subterrâneas. O fator socioambiental é um determinante no qual está comprometendo o recurso mediante o comportamento da população, como também o viés de políticas públicas ambientais pode inferir na disponibilidade de abastecimento imediato. Conclui-se que a população está exposta a fatores políticos, sociais e econômicos, assim, justifica a instalação e estabelecido da crise ambiental. 


\section{MATERIAL E MÉTODOS}

A presente pesquisa foi desenvolvida no Vale do Sambito, mesoregião norte do Estado do Piauí, especificamente nos municípios de Inhuma - PI (Figura 1) e Valença do Piauí - PI (Figura 2), aquele situado a $245 \mathrm{~km}$ da capital Teresina e este a $210 \mathrm{~km}$ da mesma. Sendo que, o município de Inhuma possui uma área de $1.027,42 \mathrm{~km}^{2} \mathrm{e}$ Valença $1.350,519 \mathrm{~km}^{2}$ de limites municipais. O presente estudo foi idealizado em dois momentos: 1) coleta de dados a partir de entrevistas; e 2) utilização de método estatístico de análise de variância (ANOVA). Nesses municípios foram aplicados questionários semiestruturados mediante a contribuição da população local a fim de obter dados acerca da compreensão da temática ambiental em sua vertente de recursos hídricos, práticas racionais de preservação e conservação de recursos naturais, hábitos de consumo e políticas públicas ambientais. Houve coleta de dados governamentais e registro de informações locais. Após a coleta de dados locais, lançou-se mão da base estatística mediante o uso do software Sisvar versão 5.6 sendo este um programa de análise, estatística e planejamento de experimentos (FERREIRA, 2011). Com a análise de variância executada pelo software, é possível medir a probabilidade estatística que um determinado fator possui sobre os demais e, assim, inferir tendências a partir de médias alternadas calculadas a partir dos dados obtidos.

Figura 1- Inhuma - PI

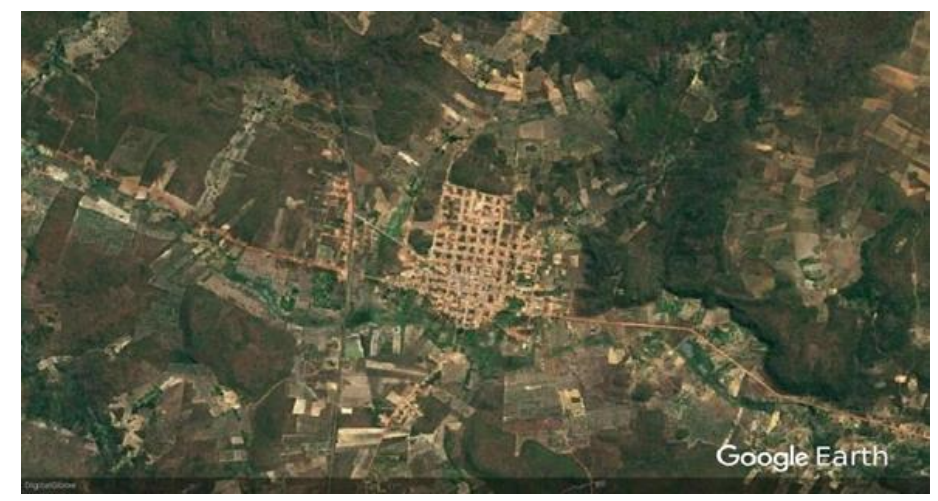


Fonte: Google Earth, 2018. Zona urbana do município de Inhuma 6³9'59" S 414ㄴ'30" W 8 km.

Figura 2 - Valença - PI

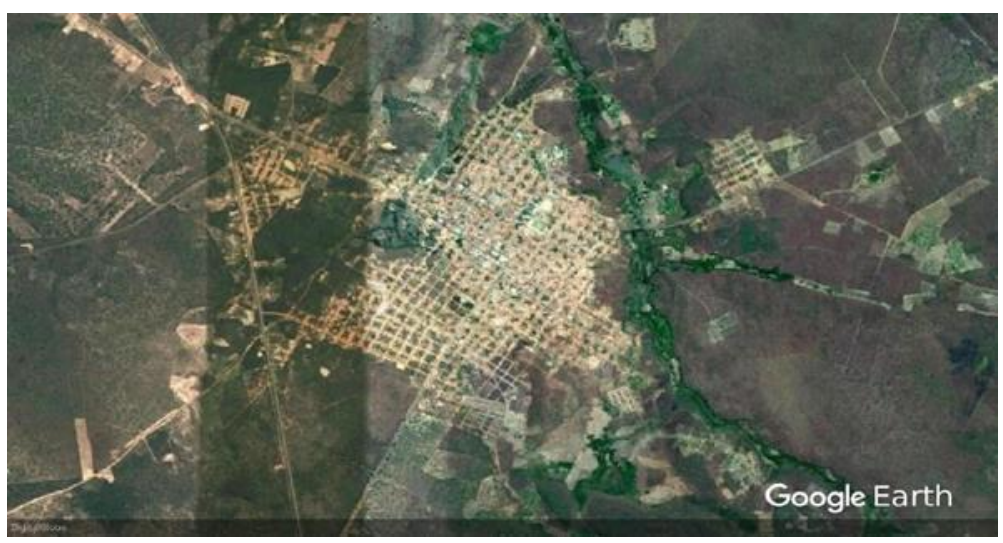

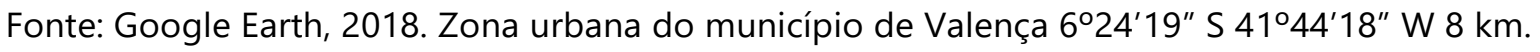

\section{ANÁLISE DOS DADOS}

\subsection{Questionários aplicados}

O presente estudo foi desenvolvido sumariamente na zona urbana dos municípios de Inhuma e Valença no estado do Piauí. Para o total de indivíduos entrevistados, 72\% são proprietários de casa própria e $22 \%$ possuem a concessão das mesmas para a sua moradia ou de suas famílias. Uma pequena parcela, $6 \%$, faz uso de imóvel de aluguel. Desta forma, observa- se que o fator temporalidade é estabelecido como contínuo, de modo que a moradia não é um fator determinante para a locomoção dos sujeitos (Gráfico 1).

\section{Gráfico 1 - Tipo de moradia}




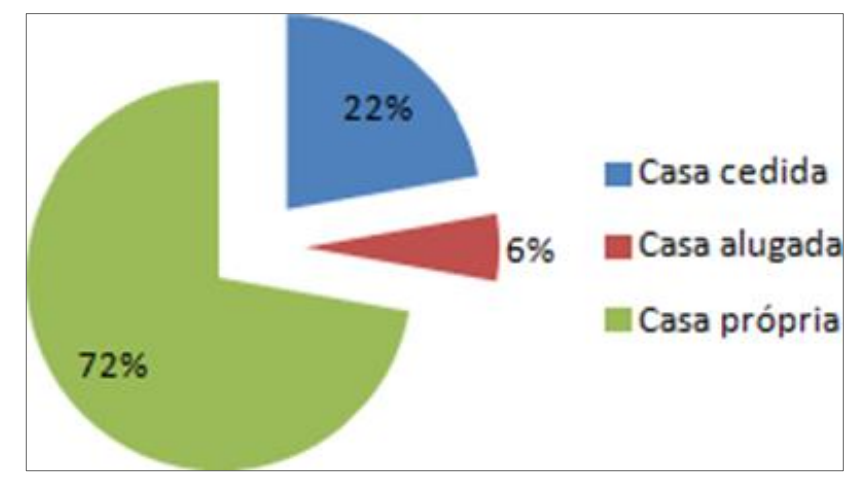

Fonte: Autores.

Denota-se que a grande maioria dos indivíduos é endêmica, estando bem adaptados com a região e conhecem bem suas características devido ao tempo que residem na mesma - $44 \%$ são nativos da região e $28 \%$ residem há mais de 10 anos, uma pequena parcela (11\%) pode-se considerar recente, residindo localmente entre 2 e 5 anos (Gráfico 2).

\section{Gráfico 2 -Tempo de residência}

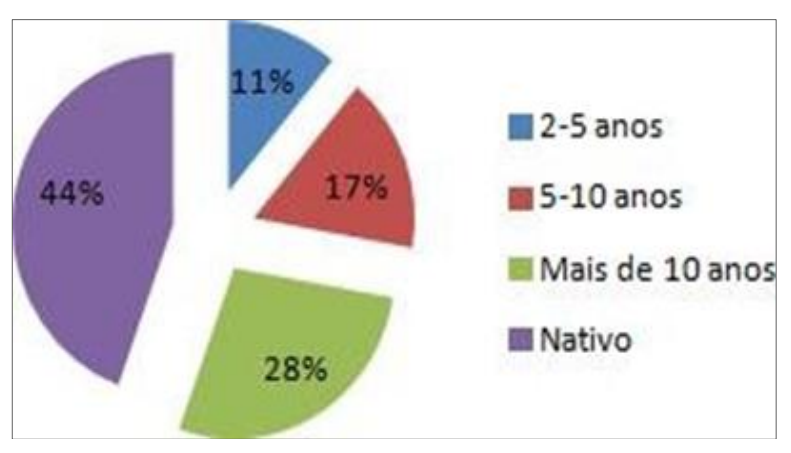

Fonte: Autores.

De acordo com o Gráfico 3, somadas as variantes de 1 e 1-2 salários mínimos, os indivíduos são em sua grande maioria, segundo os indicadores de classes do IBGE, pertencentes a classe de baixa renda, correspondendo a um total de $55 \%$. Entretanto, para os indicadores de classe média estabelecidos pelo IBGE, somadas as variantes de 3-4, 5-6 e mais de 6 salários mínimos, os indivíduos enquadrados como de classe média dão origem a um conglomerado de 45\%. A variante renda apresenta-se com padrões sumariamente heterogêneos, apresentando dois (2) 
padrões econômicos populacionais locais: os de baixa renda e de classe média. Outro quesito observado é quanto à profissão e formação: em sua grande maioria são profissionais de cargos públicos, com formação superior e que atuam em diversos setores, dentre eles, a educação básica.

\section{Gráfico 3 - Renda}

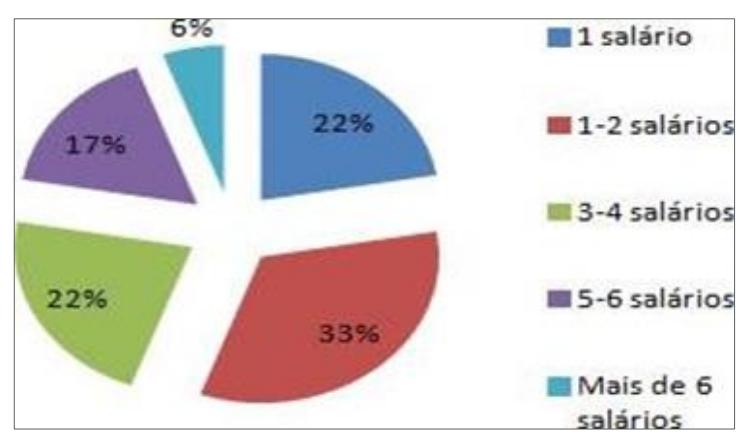

Fonte: Autores.

Para os indivíduos entrevistados, $89 \%$ ao longo dos anos notaram crescimento nas regiões de ambos os municípios. Essa observação converge com a contagem populacional entre censos do IBGE que aponta, de fato, crescimento para ambas as regiões. Podendo ser fruto de melhores oportunidades, oferta de emprego, baixa taxa de emigração ou maior nível educacional populacional tornando o mercado local mais atraente. Apenas $11 \%$ considera que não houve crescimento populacional, divergindo da maioria (Gráfico 4).

\section{Gráfico 4 - Observaram crescimento populacional}




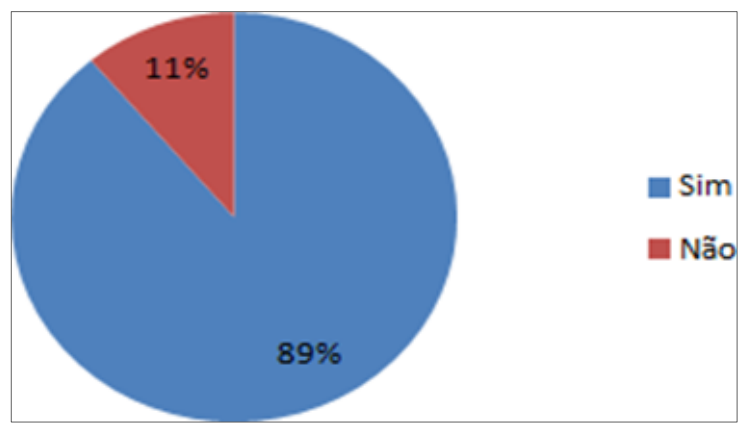

Fonte: Autores.

O Gráfico 5 revela um padrão de divergência para a região: os moradores se opõem quanto ao quesito qualidade de vida. Para metade deles a região apresenta meios que satisfazem a necessidade de bem estar quanto à qualidade de vida, entretanto, para a outra metade, a região apresenta deficiência em oferecer um ambiente minimamente adequado para habitação.

\section{Gráfico 5 - Satisfação quanto à qualidade de vida}

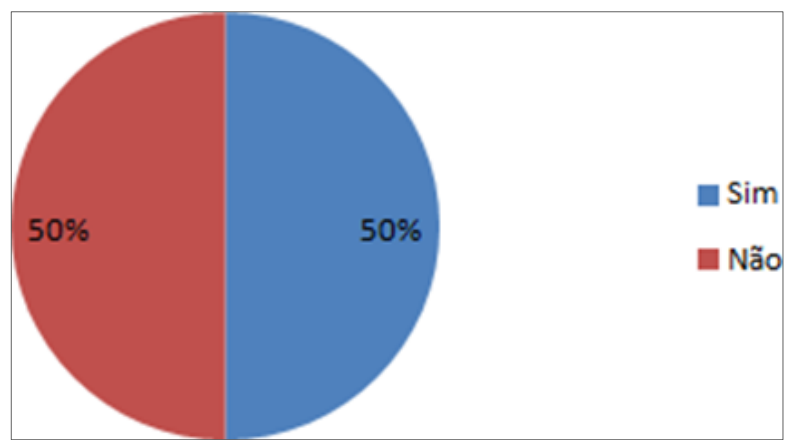

Fonte: Autores.

Em contraponto com o gráfico anterior, o Gráfico 6 revela que os indivíduos entrevistados que responderam "não" a variante de qualidade de vida compõem o contingente posterior dos que acreditam possuir saneamento básico, formando $61 \%$ do percentual. Para 39\% a região não possui nenhum tipo de saneamento básico, sendo que, o descarte de resíduos e efluentes é feito a céu aberto pela população e empresas.

\section{Gráfico 6 - Acreditam na execução de saneamento básico}




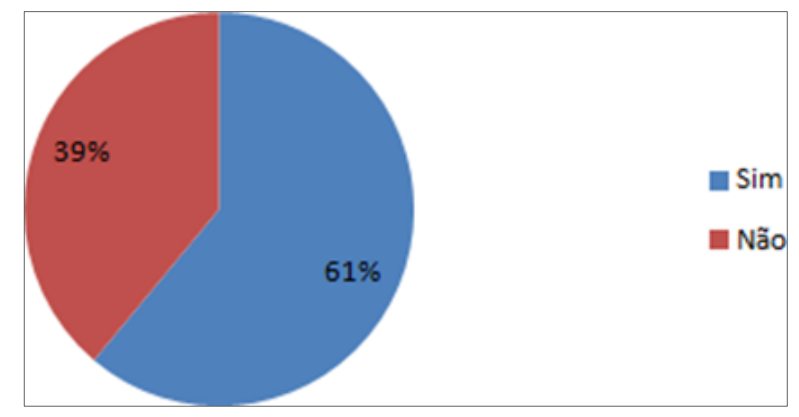

Fonte: Autores.

A coleta regular de lixo ocorre normalmente e está presente semanalmente para $83 \%$ dos entrevistados, para $17 \%$ não existe coleta regular de lixo. No entanto, a maioria dos entrevistados concorda em um quesito: o destino final do lixo. O mesmo é direcionado para o meio ambiente sem nenhum método de segurança ou proteção do mesmo. Apenas um entrevistado apontou existir aterro sanitário na região (Gráfico 7).

\section{Gráfico 7 - Coleta regular de lixo}

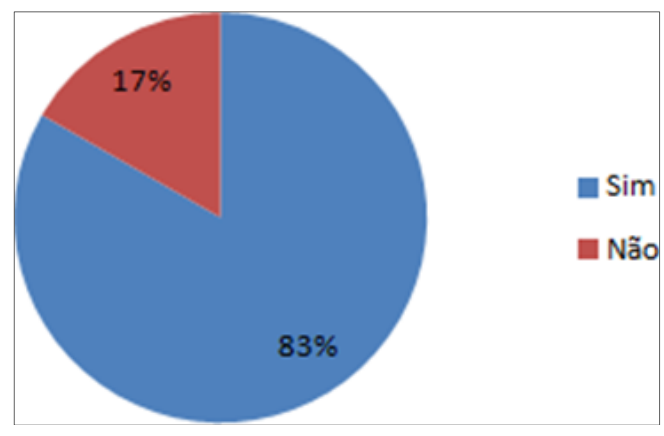

Fonte: Autores.

Em uma perspectiva de aproveitamento do potencial agrícola regional, apenas $22 \%$ afirmaram cultivar culturas vegetais, seja para subsistência ou comércio. $78 \%$ afirmaram não exercer nenhuma prática correspondente à agricultura (Gráfico 8).

\section{Gráfico 8 - Praticam agricultura}




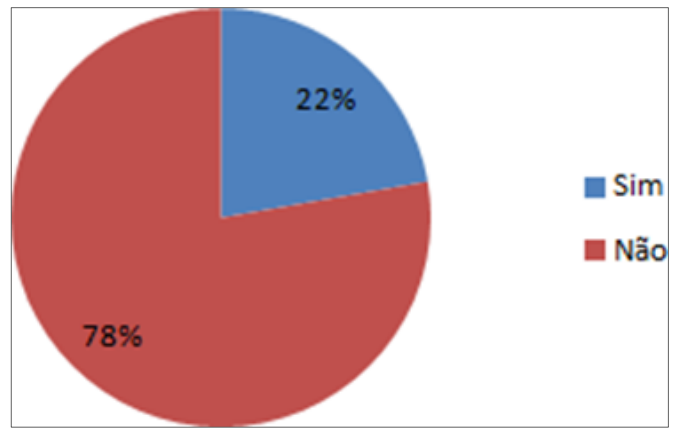

Fonte: Autores.

No Gráfico 9, segundo $76 \%$ dos indivíduos, a região possui problemas de ordem ambiental visíveis pela população. Para $24 \%$ a região encontra-se equilibrada quanto à manutenção de suporte dos ecossistemas locais, não apresentando impactos negativos oriundos de atividades antrópicas.

\section{Gráfico 9 - Identificam problemas ambientais na região}

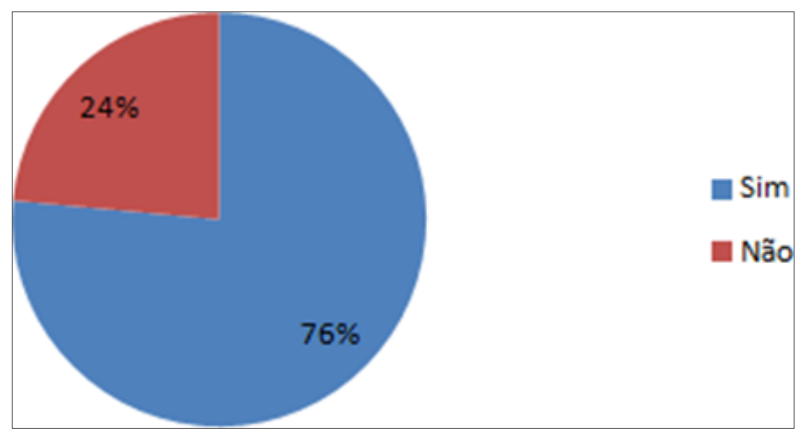

Fonte: Autores.

A variante dos que "acreditam existir programas de poços para a agropecuária" no

Gráfico 10 revela que $78 \%$ não acreditam na implementação de políticas públicas ambientais para o desenvolvimento econômico regional, já que, a economia estadual é baseada majoritariamente na agropecuária. Para $22 \%$ existe implantação de mecanismos 
que evitam a distorção causada pela crise hídrica regional e que compromete o desenvolvimento local.

\section{Gráfico 10 - Acreditam existir programas de poços para a pecuária}

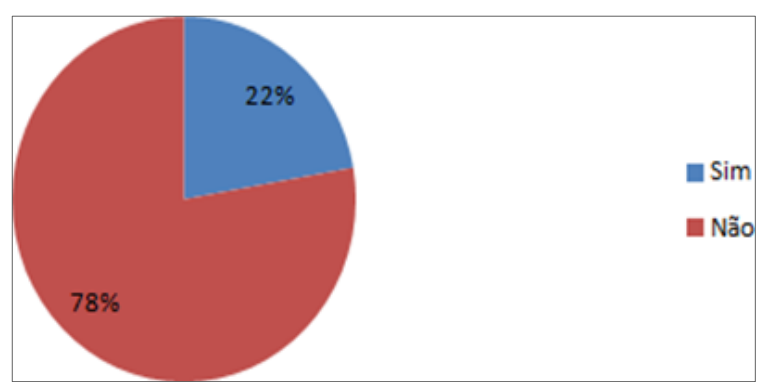

Fonte: Autores.

Para $61 \%$ da população de ambos os municípios o abastecimento de água encontra-se regular e operante pela concessionária regional, apenas 39\% afirmaram sofrer com problemas de ordem no fornecimento de água encanada até as suas residências informando existir períodos de ausência no abastecimento anualmente. Alguns fatores podem ser levados em conta para essa variante, como: localização, equipamentos, orçamento, verbas, dentre outros (Gráfico 11).

\section{Gráfico 11 - Falta no abastecimento de água}

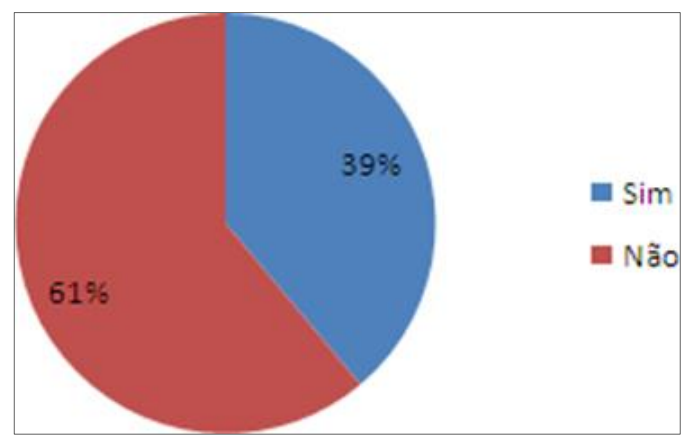

Fonte: Autores.

Para o Gráfico 12 foi perguntado aos entrevistados sobre a compreensão desses sujeitos acerca da crise hídrica regional. Para $89 \%$ a seca da região é oriunda de fatores ambientais, ou seja, a concentração e pouca pluviometria anual na região seria a 
principal causadora da seca, e tem influência direta com a produtividade. 5\% acredita ser um problema de gestão e tomada de decisão pública, como também, racionalização da população. $6 \%$ preferiu não opinar.

\section{Gráfico 12 - Origem da crise hídrica no Piauí}

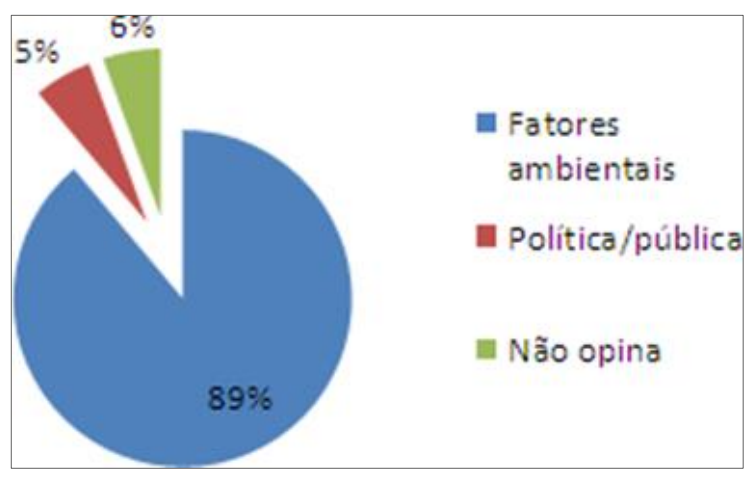

Fonte: Autores.

\subsection{Análise estatística}

Os resultados dos questionários aplicados nas cidades de Inhuma-PI e Valença do Piauí-PI foram submetidos à análise de variância (ANOVA) pelo teste Tukey, com $5 \%$ de probabilidade, resultando em médias alternadas e comparadas (VIEIRA, 2006). A análise foi calculada no software estatístico SISVAR (FERREIRA, 2009).

Tabela 1 - Principais fatores significativos acerca da compreensão da população quanto à crise hídrica e o meio ambiente

\begin{tabular}{|l|l|l|}
\hline \multicolumn{1}{|c|}{ ANÁLISE } & INHUMA & VALENÇA \\
Moradia própria & $54 \pm 49,6^{\mathrm{a}}$ & $50 \pm 53,8^{\mathrm{a}}$ \\
Nativos da região & $50 \pm 49,6^{\mathrm{a}}$ & $54 \pm 53,8^{\mathrm{a}}$ \\
Crescimento Populacional & $43 \pm 49,6^{\mathrm{a}}$ & $61 \pm 53,8^{\mathrm{a}}$ \\
Qualidade de vida local & $52 \pm 49,6^{\mathrm{a}}$ & $52 \pm 53,8^{\mathrm{a}}$ \\
Possuem Saneamento Básico & $55 \pm 49,6^{\mathrm{a}}$ & $49 \pm 53,8^{\mathrm{a}}$ \\
Possuem coleta de lixo & $50 \pm 49,6^{\mathrm{a}}$ & $54 \pm 53,8^{\mathrm{a}}$ \\
Praticam Agricultura & $45 \pm 49,6$ & $59 \pm 53,8^{\mathrm{a}}$ \\
Identificam Problemas Ambientais & $46 \pm 49,6^{\mathrm{a}}$ & $58 \pm 53,8^{\mathrm{a}}$ \\
Ausência no fornecimento de água & $55 \pm 49,6^{\mathrm{a}}$ & $49 \pm 53,8^{\mathrm{a}}$ \\
\hline
\end{tabular}


Crise hídrica está associada a fatores ambientais

$50 \pm 49,6^{\mathrm{a}}$

$54 \pm 53,8^{a}$

Fonte: Autores.

*Médias seguidas pela mesma letra não diferem significativamente entre si, a $5 \%$ de probabilidade, pelo teste Tukey.

C. v: 11.13

D. M. S: $\pm 5,8$

F: 0.1370

Para a análise estatística teve se como critério norteador de análise as perguntas que potencialmente direcionariam a um provável impacto ambiental e a percepção ecossistêmica da população, seja ela físico-natural ou administrativa da região a qual residem, assim, listou-se as principais perguntas que poderiam indicar, direcionar ou resultar em um comportamento e compreensão por parte da população. Ressalta-se que para o teste selecionou-se apenas as perguntas com respostas afirmativas ( $\mathrm{sim}$ ) nos dois municípios para que se calcula-se as suas médias e mensurasse a tendência entre ambas.

Obtido o resultado dos cálculos após aplicar o teste Tukey, observou-se que a alternância das duas médias obtidas não possui significância. Ou seja, as médias para as duas cidades não expressam diferenças significativas, sendo que, as duas, no geral, estão incluídas no mesmo padrão. Desta forma, estatisticamente, o comportamento da população das duas cidades para este estudo não divergem. A probabilidade que Inhuma ou Valença revelem comportamentos opostos é quase que nula, não existe, pois, a probabilidade (F: 0,1370$)$ foi inferior a $5 \%$.

\section{INTERPRETAÇÃO E CONSIDERAÇÕES ACERCA DOS RESULTADOS OBTIDOS}

A questão da escassez dos recursos hídricos é tema atual e de abrangência global, visto que, cada vez mais a recarga dos mananciais superficiais e subterrâneos diminuem devido a fatores de origem antrópica ou naturais. A disponibilidade de água no mundo é tema recorrente em termos de pesquisas científicas e de mobilização de entidades públicas e privadas para que se chegue à sustentabilidade do recurso, a exemplo temos, principalmente, a Lei das Águas (9.433/97), ANA (Agência Nacional das Águas), CPRM 
(Conselho de Produção de Recursos Minerais), PERH (Plano Estadual de Recursos Hídricos), SEMAR (Secretaria Estadual do Meio Ambiente e Recursos Hídricos), dentre órgãos municipais.

Diversas ações de cunho governamental, científicas, tecnológicas e mobilizadoras da sociedade civil organizada tentam nortear para a sustentabilidade do recurso, através de políticas públicas ambientais. A discussão dos resultados apresenta os pontos chaves para os quais nas regiões de Inhuma e Valença a crise hídrica se instala.

O presente estudo contou com a participação de indivíduos sumariamente valencianos e inhumenses, o que denota total compreensão acerca do território e suas transformações locais ao longo do tempo, já que, residem há mais de 10 anos. Para a perspectiva socioambiental, ponto que chama a atenção após a interpretação dos resultados é que, mediante as informações cedidas pelos indivíduos, compreende-se que em grande maioria são profissionais de classe média provendo cargos públicos e, em maior parte, são professores atuantes das redes públicas de ensino.

Esses dados denotam que o quesito Educação Ambiental permanece como algo utópico independente da classe social ou de seu poder aquisitivo, e que, a compreensão acerca de desenvolvimento sustentável além ser algo incompreendido também é negligenciado. Já que, Educação Ambiental e Meio Ambiente estendem-se por todo o currículo escolar da educação básica nacional através de documento público disponibilizado pelo MEC (2013), como política norteadora do ensino em todas as redes e sistemas de ensino, os Parâmetros Curriculares Nacionais.

Entende-se que, as classes sociais mais altas que possuem maior acesso a informação e educação de alto nível em conjunto com os profissionais competentes e responsáveis por aplicar as políticas referentes à educação, convergem com a população de baixa renda e periférica brasileira: não sabem aplicar ou não compreendem o significado da preservação do meio ambiente, neste ponto compreende-se o desperdício e a crise que este recurso vem enfrentando. Em breve analogia entre as classes sociais e a tipificação das economias, podemos identificar movimento correlato descrito por Celso 
Furtado (1973) em que o subdesenvolvimento era parte de um fenômeno histórico singular, sendo que, a caracterização das economias subdesenvolvidas (periféricas) em contraste com as desenvolvidas (centrais) deveriam ter procedimentos analíticos. Segundo Celso Furtado (1973), de acordo com a evolução do capitalismo, as economias centrais repassam seus hábitos de consumo e desperdício para as economias em desenvolvimento. Assim o é entre as classes sociais, os mais ricos fazem o mesmo repasse para os mais pobres na sociedade.

Para as variantes "qualidade de vida", "saneamento básico" e "problemas de ordem ambiental", em sua interpretação percebe-se certa confusão dos indivíduos ao dividirem-se em, acreditar ou desacreditar, em viver em um ambiente com a oferta básica pra uma vida digna em paralelo com respeito e preservação do meio ambiente, entretanto, os mesmos indivíduos ao acreditarem na qualidade de vida local desacreditam totalmente possuir saneamento básico local.

As duas vertentes são associações mútuas e dependentes para que, de fato, possase dizer que a vida tem qualidade. Características, como: aterro sanitário, adequada rede de tratamento de esgoto, tratamento adequado das águas para abastecimento, gestão e planejamento de resíduos municipal, são alguns exemplos ausentes em ambos - apesar de Valença possuir secretaria de meio ambiente, no caso de Inhuma, nem se quer houve implantação. Esses fatores básicos de qualidade de vida estão ausentes em sua totalidade em ambos os municípios, comprometendo assim a qualidade dos recursos hídricos das suas sub-bacias.

Outro ponto a chamar atenção é a vertente de "problemas de ordem ambiental", a maioria dos entrevistados acredita que a região sofre com ela. Comparando essas vertentes percebemos que a população confunde conceitos e práticas, principalmente quando aplicados localmente, na sua própria região (SACHS, 2007). Esse descaso a oferta e acesso a informação, sem uma ação proativa, ao decorrer do tempo compromete a qualidade de vida dos mesmos, os expondo a doenças, desequilíbrios ambientais e 
gerando impactos altamente nocivos ao ecossistema podendo ser passíveis de não recuperação.

O saneamento básico é fator crucial para que os mananciais permaneçam saudáveis e com recursos hídricos adequados para abastecimento da população. Assim, como se reafirmam as previsões de um ambiente insustentável e quase inabitável até 2050 (DALY, 2018).

Documentos oficiais como o encarte sobre recursos hídricos da ANA (2015) dentre outros, revelam que o maior potencial hídrico da região nordeste se situa na Bacia Hidrográfica do Parnaíba, no Piauí. No entanto, majoritariamente os participantes revelaram não cultivar agricultura, nem de subsistência, nem comercial, algo que chama a atenção já que no ramo de empreendimentos o Piauí destaca-se exatamente pela vertente agropecuária, possuindo solos muito férteis (PERH, 2010).

Programas governamentais locais para apoio de perfuração de poços para contenção da seca e agropecuária são desconhecidos por quase todos os indivíduos, de fato, esses programas são escassos. Recentemente, o Denocs (Departamento Nacional de Obras Contra as Secas) em menos de 10 anos reduziu sua força de trabalho local de 10.000 funcionários para 1.500. Nesse quadro, com cenários acentuados de períodos chuvosos e secos, compreende-se a baixa produtividade e o comum decreto anual dos municípios em estado de emergência por causa das secas.

$O$ investimento frequente esporadicamente em carros pipas poderia ser revertido em programas de perfuração de poços de acordo com a densidade e a necessidade da região atingida. Com uma gestão e planejamento adequado à região, seria revertido o quadro de Estado com maior registros de poços oficiais no sistema SIAGAS do CPRM e um dos Estados com maiores e intensos períodos de secas anuais, e poderia, hipoteticamente, resolver uma questão econômica e social.

É notável que ao se tratar de abastecimento de água os indivíduos que participaram do estudo portam-se confusamente. A maioria acredita ter água regular periodicamente em suas casas, entretanto, uma breve pesquisa in loco revela que o 
cotidiano de ambas as populações não é de água regular, sendo intercalado ao fornecimento do recurso a sua indisponibilidade também.

A Bacia do Poti (PERH, 2010), onde os dois municípios se inserem faz parte da Bacia Sedimentar do Parnaíba, que como já vimos é uma das mais ricas em recursos hídricos do Brasil. Ao chegar nesse quesito vem à luz da reflexão a problemática: o que de fato ocorre para que o recurso subterrâneo não seja explorado adequadamente, liberando todo seu potencial para a população local? Dentre as muitas respostas existem as de ordem política, é necessária uma articulação entre os poderes, formulando políticas e disponibilizando verbas que sejam capazes de suprir a demanda da região, que é pequena. Não existe uma gestão, planejamento ou monitoramento para o fornecimento de água, isso impacta negativamente a população, pois a mesma fica refém de problemas individuais, coletivos e econômicos.

Em alguns municípios piauienses a seca acomete e castiga a região devido à disponibilidade do recurso, no entanto, não é o caso dos municípios em questão. É necessário investimento em equipamentos de captação, hidráulicos, bombeamento e tratamento, este último basicamente inexiste, sendo utilizados métodos arcaicos de tratamento. A água deve ser tratada como prioridade, pois é dela que se desenvolve a economia e alimenta as populações; não se deve enxergá-la como um bem dispensável. Deste modo, compreende-se que a crise hídrica local é mais um fruto do poder executivo e, por que não, legislativo. Não é disponibilidade do recurso, mas sim a sua ineficiência na oferta que não atende a demanda.

Outro ponto revelador, parte da compreensão sobre a origem da seca na região. Para praticamente $100 \%$ dos entrevistados, a seca é fruto de fatores ambientais. De fato, essa percepção é algo inevitável ao analisar empiricamente a pluviometria local, porém, dados meteorológicos precisos coletados pela ANA (2015) revelam que no Piauí a precipitação anual é na faixa de aproximadamente $800 \mathrm{~mm}$. A grande questão regional é devido aos períodos de seca e chuvosos serem acentuados em alguns meses do ano, geralmente os de chuva perfazem uma faixa de 3 meses de intensa precipitação e o 
decorrer é de seca, não obstante, é natural partir da compreensão que a seca é característica ambiental.

Entretanto, o sertão ou semiárido piauiense possui água proveniente das chuvas suficiente para que a região não sofresse com a seca, o grande problema é a distribuição temporal das mesmas. As chuvas poderiam ter uma melhor distribuição anual e menor concentração mensal, assim a água pluviométrica seria suficiente para recarga dos mananciais e abastecimento da população.

Esses dados revelam que a população atrela a seca à climatologia local, devido não terem conhecimento sobre a disponibilidade hídrica subterrânea. Isso possibilita inferir que a mesma é castigada ao longo dos anos porque se impossibilita de cobrar uma intervenção do poder público para ter o fornecimento do bem mais básico. Uma população consciente e segura dos seus direitos gera uma maior cobrança e traz mais benefícios para si própria; mas para isso se faz necessário ou a dinâmica de fornecimento de informação pelo poder público através da educação e veículos de comunicação, ou o despertar da necessidade de conhecer, compreender seu território, sua região e sua cultura.

Este último ponto é algo muito característico do nordeste, se formos reconstituir ou resgatar a sua cultura, ela remete - seja através de obras literárias como de Graciliano Ramos "Vidas Secas" (2003) ou de recursos tecnológicos que sempre foram monopolizados pelo sul do país; a um lugar inóspito, sem disponibilidade de água e que obriga a família a se retirar do mesmo para não morrer de sede e fome. Esse retrato da história talvez reflita nas gerações atuais através da seca local. Porém por mais que atualmente existam problemas de ordem hídrica, não é mais necessário ir até o manancial e coletar água para sobreviver, ou então, abandonar o seu lar a procura de um com oferta de água maior - direcionando à negligenciação do fato. Desta forma, pode-se explicar, em partes, a ideia de considerarem a seca ser de ordem ambiental e aceitarem os problemas locais. 


\section{CONSIDERAÇÕES FINAIS}

A presente pesquisa possui como eixo norteador diagnosticar a crise hídrica na região através do viés socioambiental e governamental. Ao analisar cada parâmetro estabelecido como critério de identificação, análise e avalição, é mensurável que a crise hídrica regional não é oriunda de fatores ambientais. Ao analisar os estudos passados e presentes, estes fatores exercem forças sobre questões de menor representatividade e magnitude, como é o caso da temperatura ou da periodicidade das chuvas e não da sua disponibilidade. Entretanto, verifica- se que estudos recentes revelam a potencialidade da Bacia Hidrográfica que se situa sob o Piauí. De fato, ao cruzar os dados é notável que esse seja um problema de proatividade, de motivação e de pré-disposição por parte da população na busca pela informação e dela fazer usufruto.

O governo, seja municipal, estadual ou federal, tem a sua disposição os mais bem detalhados relatórios oficiais e públicos, com as características e peculiaridades a nível local, regional e nacional. No entanto, a tomada de decisão ocorre lentamente, ou, quase sempre, não ocorre, limitando-se a momentos de emergência no fornecimento de água. O Plano Estadual de Recursos Hídricos revela o potencial da região na produção de grãos e frutas, mas quando não se investe também não se desenvolve. O Estado tem solos férteis, produtivos e que, regularmente irrigados, fornecem a população subsistência e economia. Mas, para isso, carece de investimento em tecnologia e programas de manejo e custeio para o pequeno produtor rural que não possui condições de perfurar um poço em sua propriedade.

A questão ambiental é outro agravante devido à população não ser instruída adequadamente sobre Educação Ambiental. Isso reflete diretamente na preservação do recurso hídrico, de modo que, quanto mais rápido seja feita a autoavaliação dessa questão, mais rápido será tido um olhar para o futuro e, assim, não comprometer a disponibilidade para as gerações futuras. O grande problema da crise hídrica local revela-se tanto pela inércia da população quanto pelo descaso do governo, seja ele municipal ou estadual, atingindo horizontes econômicos, ambientais, políticos e sociais. 


\section{REFERÊNCIAS}

ABAS - Agência Brasileira de Águas Subterrâneas. Distrito Federal, BR. Águas subterrâneas - minimização das consequências da seca no Nordeste. Junho de 2003.

ANA - Agência Nacional de Águas. Superintendência de Planejamento de Recursos Hídricos

- SPR (Brasília, DF). Encarte Sobre a Crise Hídrica - Conjuntura dos Recursos Hídricos no Brasil. 2015.

BRASIL. Decreto 17.304 de 07 de agosto de 2017, que dispõe dos municípios em estado de emergência devido à seca. Diário Oficial [do] Estado do Piauí, Poder Executivo.

BRASIL. Decreto-Lei $n^{\circ} 63.778$ de 11 de dezembro de 1968, que dispõe sobre a regulamentação da inclusão de municípios no Polígono das Secas. Diário Oficial [da] República Federativa do Brasil, Poder Executivo.

BRASIL. Lei $n^{\circ} 9.433$ de 08 de janeiro de 1997, que dispõe Institui a Política Nacional de Recursos Hídricos, cria o Sistema Nacional de Gerenciamento de Recursos Hídricos, regulamenta o inciso XIX do art. 21 da Constituição Federal, e altera o art. $1^{\circ}$ da Lei $n^{\circ} 8.001$, de 13 de março de 1990, que modificou a Lei $n^{\circ}$ 7.990, de 28 de dezembro de 1989. Diário Oficial [da] República Federativa do Brasil, Poder Executivo.

FURTADO, C. O mito do desenvolvimento econômico. Rio de Janeiro: Paz e Terra, 1973.

CPRM - Companhia de Pesquisa de Recursos Minerais. Coord. Belo Horizonte, MG. Mickaelon B. Vasconcelos, Carlos Antônio da Luz, Maria Antonieta Alcântara Mourão. Projeto rede integrada de monitoramento das águas subterrâneas: relatório diagnóstico aquífero serra grande, bacia sedimentar do parnaíba. 2012.

DALY, Herman. Sustentabilidade em um mundo lotado. SCIENTIFIC AMERICAN BRASIL. Disponível em: http://www2.uol.com.br/sciam/reportagens/sustentabilidade_em_um_mundo_lotado.html.

FAO. Irrigation practice and water management, irrigation and drainage. Paper 1, 1988.

FEITOSA, F. A. C.; Vidal, C.; Estudos hidrogeológicos de bacias sedimentares da região semiárida do nordeste brasileiro. CPRM-Serviço Geológico do Brasil, Brasília: 2004, pág. 84.

FERREIRA, D. F. Sisvar: a computer statistical analysis system. Ciência e Agrotecnologia (UFLA), v. 35, n.6, p. 1039-1042, 2011.

HORN, Geraldo Balduíno; DIEZ, Carmem Lúcia F. Metodologia de pesquisa. Curitiba: IESDE, 2005. 
INSTITUTO BRASILEIRO DE GEOGRAFIA E ESTATÍSTICA (IBGE). População e domicílios em grade estatística. 2010. Disponível em: http://censo2010.ibge.gov.br.

MINISTÉRIO DA EDUCAÇÃO E CULTURA - MEC. Diretrizes curriculares nacionais da educação básica. Brasília: MEC, SEB, DICEI, 562p. 2013.

RAMOS, Graciliano. Vidas secas. 137 ed. Brasil: Record, 2003.

REBOUÇAS, A. C.; Água na região nordeste: desperdício e escassez. Estudos Avançados, São Paulo, vol.11, no.29, jan./abr. 1997.

SECRETARIA ESTADUAL DO MEIO AMBIENTE E RECURSOS HÍDRICOS - SEMAR. Plano estadual dos recursos hídricos. Governo Estadual do Piauí, poder executivo: 2010.

VASCONCELOS, M. B; Sousa, N. G; Genaro, D. T; Luz, C. A.; Tupinambá, M. K. F.; Histórico de perfurações de poços tubulares no estado do Piauí. Revista de Geologia, Ceará, Vol. 27, n 2, $111-126,2014$.

SACHS, I. Rumo à ecossocioeconomia: teoria e prática do desenvolvimento. São Paulo: Cortez, 2007. 